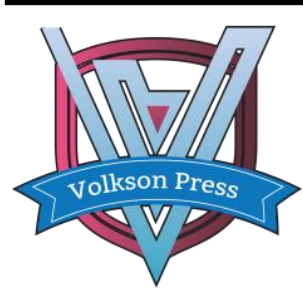

Contents List available at VOLKSON PRESS

Economics \& Management Innovations(EMI)

DOI : http://doi.org/10.26480/icemi.01.2017.302.306

\title{
Application of Tobit-Piecewise regression in Economics Data Consisting of Outliers
}

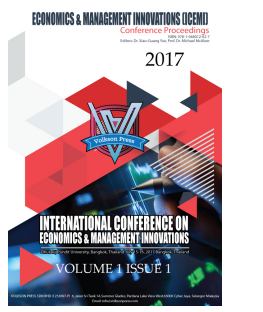

Titirut Mekbunditkul ${ }^{1}$, Nantawarn Ramdacha ${ }^{2}$, Parinya Klaicharoen ${ }^{3}$ and Skulthip Anantarag ${ }^{4}$

1,2,3,4Research Service Center, Dhurakij Pundit University, Thailand

Email : titirut.mek@dpu.ac.th

This is an open access article distributed under the Creative Commons Attribution License, which permits unrestricted use, distribution, and reproduction in any medium, provided the original work is properly cited.

\section{ARTICLE DETAILS}

\section{Article History:}

Received 02 october 2017

Accepted 06 october 2017

Available online 11 october 2017

\section{Keywords:}

Tobit-piecewise regression, Tobit regression, Piecewise regression, Limitation in dependent variable, Regression outliers

\section{ABSTRACT}

In this paper the Greeks are derived in the Piterbarg option pricing framework, which derives the price of an option through three unique interest rates, and collateral payments. The different scenarios of collateral payments are discussed, and closed form solutions for the option prices are derived. The Greeks are found for each scenario and implemented.

\section{Introduction}

It is well known that when researchers want to examine the linear influence of independent variables on dependent variables, where both are continuous variables, Ordinary Least Square (OLS) linear regression has been analysed. Results can then be used to predict the value of the dependent variable by using the characteristics of the linear relationship. The regression model can be formulated as follows:

$Y i=\beta 0+\beta 1 \times 1 i+\beta 2 \times 2 i+\ldots+\beta k x k i+\varepsilon i, i=1, \ldots, n$. Where Yi is the dependent variable,

$x 1 i, x 2 i, \ldots, x k i$ is the 1 st to $k$ th independent variable and $\beta 0, \beta 1, \beta$ $2, \ldots, \beta \mathrm{k}$ is the unknown regression coefficient. $\varepsilon$ replaces random error with the assumption that it is a normally distributed with a 0 mean and constant variance. In other words, $\varepsilon i \sim$ i.i.d.N $(0, \sigma 2)$ for all of $\mathrm{i}=1, \ldots, \mathrm{n}$ whereby the dependent variable Yi is a member of real numbers $(Y i \in R)$ with $\beta 0+\beta 1 \times 1 i+\beta 2 x 2 i+\ldots+\beta k x k i$ and constant variance.

\section{That is $\mathrm{Yi} \sim$ i.i.d.N $(\beta 0+\beta 1 \mathrm{x} 1 \mathrm{i}+\ldots+\beta \mathrm{kxki}), \sigma 2 \quad$ for all $\mathrm{i}=1, \ldots$,}

Under such assumptions, the OLS estimator will have the qualities of the best linear unbiased estimator. However, in the case where researchers have violated the assumptions, such as when the error is not a normal distribution or there is a heterogeneity, the ordinary least squares estimator will become an inadequate estimator, which will make the resulting regression equation inappropriate in predicting the value of the dependent variable the researcher intended to study. Apart from that, another important problem in evaluating regression is the problem of outliers, which [1] has stated that y-direction outliers and $\mathrm{x}$-direction outliers may result in the problem of inconstant variables. Additionally, once this problem occurs, and if the researcher uses the ordinary least squares estimator, the regression equation obtained will show a poor linear relationship. Often, when problems regarding outliers occur, most researchers would disregard all those outliers and this method will give the researchers errornous result as the disregarded outliers may be part of the population and not bad outliers.

Therefore, many statisticians have developed various methods in dealing with outliers whereby each method has one common principle: not to disregard the outliers, and instead, try to rationally decrease the influence of those outliers. This method will give the most appropriate regression equation suited to the data. One of the methods includes research done by Mekbunditkut [2] whodeveloped the Tobit-piecewise regression to decrease the influence of the outliers. The method mentioned is easier to apply than other Robust regressions. The Tobit piecewise regression was developed under two concepts: the Tobit regression concept and the Piecewise regression concept, which is described under heading 2 . In heading 3 , the writer talks about the interpretation of the parameters in the Tobit-piecewise regression and heading 4 gives examples of the application of the Tobit-piecewise regression economically as well as in other areas. Lastly, heading 5 is the process of using the Tobit-piecewise regression.

\section{The Basic Concept}

The Tobit-piecewise regression was firstly developed under 2 concepts the Tobit regression and the Piecewise regression, that are applied to reduce the influence of outliers on the evaluation of regression. The first person that developed this regression is Mekbunditkul [2] whereby the developer intended to limit the number of outliers and reduce its influence by specifying that the outliers have the same value as the upper limit and/or lower limit as the condept of Tobit regression model. Regarding the development of together model and piecewise regression model, it allowed the upper limit and/or lower limit to become an inconstant value throughout the data set and this piecewise regression is able to reduce the influence of outliers in the independent variable in some cases as well. Therefore, the author wish to describe the basic approach of each model as follows: 2.1 Tobit regression The Tobit regression model is a model developed by an economist called [3] to be used with data where the dependent variable has an upper limit and/or lower limit, which is commonly found in data that display economical features. For example, in the case that the researcher wants to study factors that influences costs in buying cars for the year 2014, the researcher will find many observed values that has a value of 0 baht as there were no car purchases made during that year and the researcher cannot disregard those observed values. That being said, although in that given year there was no car purchases made in the sample survey (expenses paid in buying cars is 0 baht), it does not mean that cars were never bought. Therefore, it is incorrect to disregard those observed values. If this situation this happens and the researcher intends to evaluate the information using the ordinary least square linear regression analysis, a biased estimator will be produced. Consider figure 1 , point 0 to point A displays the data of households that have not paid expenses in buying cars for the study year : 


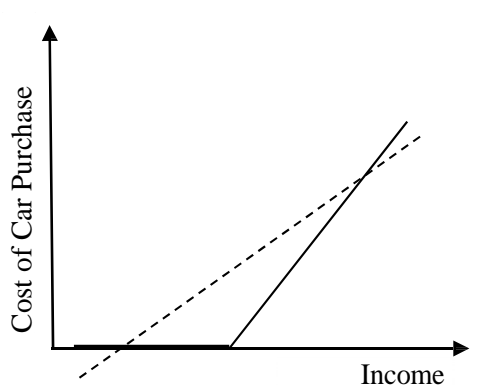

Figure 1 The relationship between household income and cost of car purchase

It can be seen that the engel curve is divided into 2 sectors from line $\mathrm{OA}$ and $\mathrm{AB}$. It can be clearly seen that household expenses paid in buying cars cannot be explained using the OLS linear regression analysis (represented by the dashed line $\mathrm{CD}$ ) since the linear regression equation $\mathrm{CD}$ has an underestimate value, where in actual fact the slope is the straight line $\mathrm{AB}$. When the data is as stated in 1958, Tobin thus suggested a way to evaluate the relationship between the independent variable and dependent variable when it is a limited dependent variable. Later on this method was named the Tobit regression analysis whereby the Tobit regression model represented a linear regression model. The Tobit regression model can be written as follows

$$
\mathrm{Yi}= \begin{cases}\mathrm{L}_{*} & ; \mathrm{Y}_{*}^{*} \leq \mathrm{L}, \\ \mathrm{Y}_{\mathrm{i}} & ; \mathrm{Y}_{\mathrm{i}}>\mathrm{L},\end{cases}
$$

where $Y_{i}, i=1, \ldots, n$ replaces the link function that is created by the linear regression equation:

$*=\beta+\beta+\ldots+\beta+\varepsilon$

$\mathrm{Y}_{\mathrm{i}} 1^{\mathrm{xi}} 1 \mathrm{k}^{\mathrm{x}} \mathrm{ik} \mathrm{i}$

where $\mathrm{X}_{1 \mathrm{i}}, \mathrm{X}_{2 \mathrm{i}}, \ldots, \mathrm{X}_{\mathrm{ki}}$ being the $1^{\text {st }}$ to $\mathrm{k}^{\text {th }}$ independent variable. Parameters $\beta_{0}, \beta_{1}, \beta_{2}, \ldots, \beta_{\mathrm{k}}$ are regression coefficients of unknown value and $\varepsilon$ represents random error with the same assumption as the regression analysis, that is, $\varepsilon \sim$ i.i.d. $N\left(0, \sigma^{2}\right)$ for all of $i=1, \ldots, n$.

\subsection{Piecewise regression}

Quant [4] developed the piecewise regression to use in the case where the linear relationship is a single regression line that is unsuitable for the data. This may be due to the fact that the discrepancy has different distributions.

The piecewise regression model in the case of two regression lines can be written as follows:

$$
Y_{i}= \begin{cases}\alpha_{1}+\beta_{1} x_{i}+\varepsilon_{i} & ; x_{i} \leq \delta \\ \alpha 2+\beta_{2} x_{i}+\varepsilon_{i} & ; x_{i}>\delta\end{cases}
$$

when $Y^{i} i=1, \ldots, n$. is the dependent variable, $X_{i}$ is the independent variable $\begin{gathered}\alpha, \alpha \beta \\ 1,2,1,2\end{gathered}$ are the regression coefficients of unknown value and $\varepsilon_{\mathrm{i}}$ is $\varepsilon_{\mathrm{i}} \sim$ i.i.d.N $\left(0, \sigma^{2}\right)$ for all $\mathrm{i}=1, \ldots, \mathrm{n}$.

Equation (3) can be written in the form of a linear regression model that has a dummy variable, as seen in equation (4)

$$
\begin{aligned}
& \mathrm{Y}_{\mathrm{i}}=\alpha_{1}+\beta_{1} \mathrm{x}_{\mathrm{i}}+\beta_{2}\left(\mathrm{x}_{\mathrm{i}}-\delta\right) \mathrm{D}_{\mathrm{i}}+\varepsilon_{\mathrm{i}} \\
& \text { where } \mathrm{x}_{\mathrm{i}}^{*}=\left(\mathrm{x}_{\mathrm{i}}-\delta\right) \mathrm{D}_{\mathrm{i}} \text { and } \mathrm{D}_{\mathrm{i}}=\left\{\begin{array}{l}
0 ; \mathrm{x}_{\mathrm{i}} \leq \delta \\
1 ; \mathrm{xi}>\delta
\end{array}\right.
\end{aligned}
$$

\subsection{Tobit-piecewise regression}

The Tobit-piecewise regression model was developed by Mekbunditkul [2] to be used for regression analysis in the case of regression outliers problem.

The Tobit-piecewise regression is written as seen in equation $(5)^{1}$

where $\mathrm{Y}_{\mathrm{i}}^{*}=\alpha_{1}+\beta_{1 \mathrm{i}} \mathrm{x}_{2}+\beta_{2} \mathrm{x}^{*}+\varepsilon, \mathrm{i}_{\mathrm{i}} \mathrm{L}_{0}=\left\{\begin{array}{ll}\mathrm{U}_{0} & ; \mathrm{x}_{\mathrm{i}} \leq \delta \\ \mathrm{Y}_{\mathrm{b}} & ; \mathrm{x}_{\mathrm{i}}>\delta\end{array}\right.$ and $\mathrm{U}_{0}= \begin{cases}\mathrm{U}_{\mathrm{a}} & ; \mathrm{x}_{\mathrm{i}} \leq \delta \\ \mathrm{U}_{\mathrm{b}} & ; \mathrm{x}_{\mathrm{i}}>\delta\end{cases}$ and $x_{i}^{*}=\left(x_{i}-\delta\right) D_{i}$ where $D_{i}$ is the dummy variable that has the

following value $D=\left\{\begin{array}{l}0 ; x_{i} \leq \delta \\ 1 ; x_{i}>\delta\end{array}\right.$

To determine the parameter values in the Tobit-piecewise regression model, Mekbunditkul [2] utilized the method of Maximum likelihood estimation. Therefore, the estimated regression coefficients were of good quality following the maximum likelihood estimation including consistency and best asymptotically normal (B.A.N.). The developer has applied the model in many cases where there are problems with evaluation of regression due to outliers, as presented under heading 5 .

\section{The Evaluation of Parameters in the Tobit-Piecewise Regression Model}

Since the Tobit-piecewise regression model was developed from two concepts as mentioned, the interpretation of parameter values in the model will be different from the interpretation of parameter values in the OLS linear regression analysis. The author has described the interpretation of the parameters in this heading by using the Tobit regression model with a lower limit of 0 with no upper limit, to make it easier to understand, and above mentioned scenario is specific to the Tobit- piecewise regression model. In 1980, McDonald and Moffitt [5] demonstrated that the regression coefficients in the Tobit regression model did not have the same meaning as the regression coefficients in the traditional regression model. This is because when the value of the independent variable changes by one unit, it not only has an influence on the dependent variable following the value of the parameters linked to the independent variable, but also has an influence on the change of the probability of the dependent variable as well.

Details are as follows: From equation (1), where $L=0$, the expected value of $Y$ is the following:

$$
\mathrm{E}(\mathrm{Y})=\mathrm{x} \beta \Phi(\mathrm{z})+\sigma \phi(\mathrm{z})
$$

when the standardized normal value of $Y$ or in other words, $z=x \beta / \sigma$ and the conditional expected value of $\mathrm{Y}^{*}$ is the following:

$$
\mathrm{E}\left(\mathrm{Y}^{*} \mid \mathrm{Y}^{*}>0\right)=\mathrm{x} \beta+\frac{\sigma \phi(\mathrm{z})}{\% \% \Phi},
$$

Therefore, from equation (6) and (7), we will get

$\mathrm{E}(\mathrm{Y})=\mathrm{E}\left(\mathrm{Y}^{*} \mid \mathrm{Y}^{*}>0\right) \Phi(\mathrm{z})$

We can found that the influence of the change of the independent variable at $j$ or with the following $X_{j}$ on $Y$

$$
\begin{aligned}
\frac{\partial \mathrm{E}(\underline{\mathrm{Y}})}{\partial \mathrm{X}_{\mathrm{j}}} & =\Phi(\mathrm{z}) \frac{\partial \mathrm{E}\left(\mathrm{Y}^{*} \mid \mathrm{Y}^{*}>0\right)}{\partial \mathrm{X}_{\mathrm{j}}} \\
& +\mathrm{E}\left(\mathrm{Y}^{*} \mid \mathrm{Y}^{*}>0\right) \frac{\partial \Phi(\mathrm{z})}{\partial \mathrm{X}_{\mathrm{j}}}
\end{aligned}
$$

$j=1,2, \ldots, k$.

From equation (8), it can clearly be seen that the change of the dependent variable $Y$ consists of two main components, which are: 1) the change of the dependent variable when the observed value is higher than the lower limit

$\left(\mathrm{Y}_{2}\right)$ that was weighted using the cumulative probability distribution function $Y^{*}$ as seen in the first term of equation (8), and

2) change in probability of the dependent variable when the observed value is higher than the lower limit (Y2) that was weighted by the conditional expected value of $\mathrm{Y}^{*}$ as shown in the second term of

equation (8). The ratio $\underline{\partial \mathrm{E}}(\underline{\mathrm{Y}})$ and $\underline{\partial \mathrm{E}}\left(\underline{\mathrm{Y}}^{*}-\underline{\mathrm{Y}}^{*}-\underline{ }-\underline{0}\right)$ is called the

$$
\partial \mathrm{X}_{\mathrm{j}} \quad \partial \mathrm{X}_{\mathrm{j}}
$$

marginal effect and conditional marginal effect, respectively. The value of the two ratios can be found via the following steps: The conditional expectation of the dependent variable when the observed value is higher than the lower limit is as follows:

$\mathrm{E}\left(\mathrm{Y}^{*} \mid \mathrm{Y}^{*}>0\right)=\mathrm{x} \beta+\mathrm{E}(\varepsilon \mid \varepsilon>-\mathrm{x} \beta)$ 


$$
\begin{array}{cc}
\text { where } & \% \% \\
\mathrm{E}(\varepsilon \mid \varepsilon>-\mathrm{x} \beta)= & \sigma \phi\left(\frac{-\mathrm{x} \beta / \sigma}{\% \%}\right) \\
\% \% & 1-\Phi\left(\begin{array}{c}
-\mathrm{x} \beta / \sigma \\
\% \%
\end{array}\right)
\end{array}
$$

Therefore,

$\mathrm{E}\left(\mathrm{Y}^{*} \mid \mathrm{Y}^{*}>0\right)=\mathrm{x} \beta+\underline{\sigma \phi}(\mathrm{z})$

$$
\% \Phi(\mathrm{z})
$$

$$
\mathrm{z}=\mathrm{x} \beta / \sigma
$$

Therefore,

$$
\left.\frac{\partial \mathrm{E}\left(\mathrm{Y}^{*} \mid \mathrm{Y}^{*}>0\right)}{\partial \mathrm{X}_{\mathrm{j}}}=\left.\beta_{\mathrm{j}}\right|^{1-} \frac{\mathrm{z} \phi(\mathrm{z})}{\Phi(\mathrm{z})}-\frac{(\phi(\mathrm{z}))^{2}}{(\Phi(\mathrm{z}) \boldsymbol{)}}\right)
$$

Substituting equation (9) into equation (8), y ou will get

$$
\begin{aligned}
& \begin{array}{l}
\phi \\
\phi
\end{array} \\
& \partial \mathrm{X}_{\mathrm{j}} \\
& \text { ( ) }(())
\end{aligned}
$$

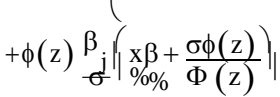

and from equation (10) we will get $\frac{\mathrm{E}(\mathrm{Y})}{\partial \mathrm{X}_{\mathrm{j}}}=\beta \mathrm{j} \Phi(\mathrm{z})$ It can be clearly

seen that the influence of the change of the independent variable $\mathrm{Xj}$ with respect to $\mathrm{Y}$ depends on the regression coefficient of the Tobit regression multiplied by the cumulative density function of the observed value that has a higher value than the lower limit $\left(\mathrm{Y}_{2}\right)$. Therefore, if the researcher wants to apply the Tobit regression model or the Tobitpiecewise regression model in their research, they should interpret the regression coefficients as stated by their concept.

\section{Application of the Tobit-Piecewise Regression Model}

\subsection{Comparing regression lines}

In the year 2010, Mekbunditkut [2] compared 4 different types of regression lines, which are: linear least square regression, Tobit regression line, Piecewise regression line and Tobit-piecewise regression line with the following 3 data sets: Data set 1 involves American and Boston stock exchanges, Data set 2 involves brain and body weight and Data set 3 involves shipping information. Results of the analysis are displayed in figure 2(a) - 2(c). From results of the analysis as shown in figure 2(a) - 2(c), it can be seen that in the case where the data is an outlier in the $(\mathrm{y}$ - direction) but is an outlier that has minimal influence on the regression

line as seen in the data in figure 2(a), all 4 different types of regression lines barely have any significance differences between them. However, if the data evaluated by the researcher has an outlier that is quite influential towards the regression line, the linear least square regression will be the least suitable line for the data under consideration as seen in figures 2 (b) - 2(c). It can be clearly seen that the linear least square regression line is the most distant from the majority of the data. On the other hand, the Tobit- piecewise regression line will be the most suitable line for the data and give the lowest R.E.2 (Relative efficiency) value compared to the other 3 models.

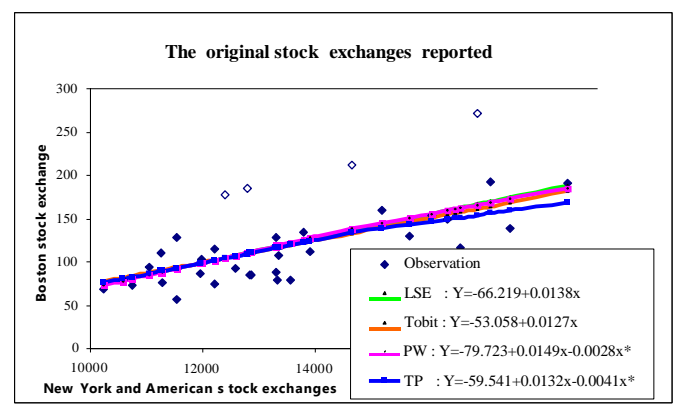

Figure 2(a) Four regression lines for the stock exchange data Source: Mekbunditkul [2]

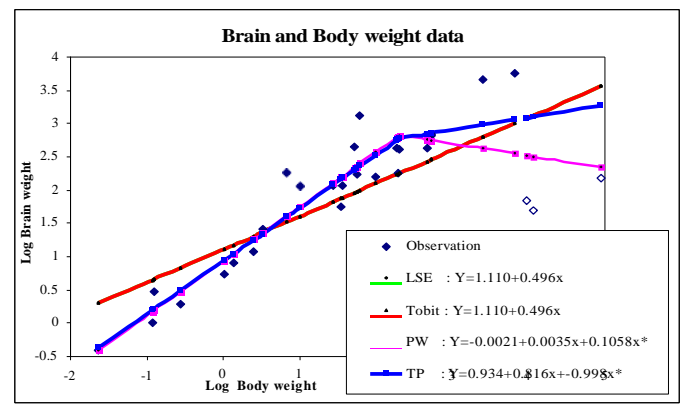

Figure 2(b) Four regression lines for brain and body weighted data Source: Mekbunditkul [2]

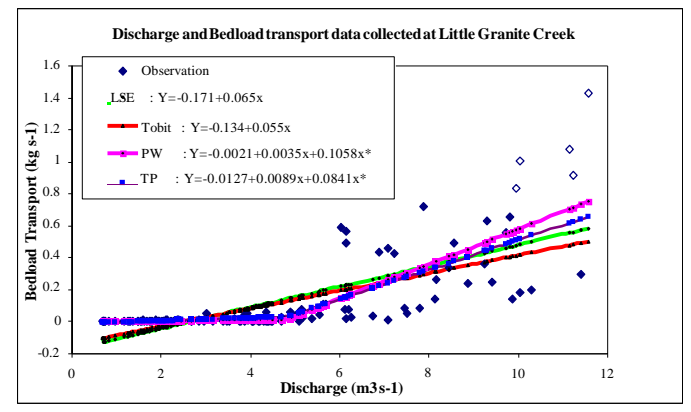

Figure 2(c) Four regression lines for discharge and bedload transport data Source: Mekbunditkul [2]

\subsection{Results of economics analysis}

In this heading, the author emphasizes the application of the Tobit regression model (specific cases for usage of the Tobit-piecewise regression model) and the Tobit-piecewise regression model in the analysis of real data that will be useful for researchers.

\subsubsection{Economics analysis of data using the Tobit regression model}

Presently, many researches used the Tobit regression model in their research as current data that have lower limits and/or upper limits, especially data concerning education economics such as education expenses, education fee incomes, budgets, etc. This article will refer two studies that has applied the Tobit regression model in education economics whereby the two studies concerned have a dependent variable that is the expenses data, which has an absolute lower limit of 0 (or possibly more). The author has summarised the studies the application and interpretation of analysis results as follows:

In 2006, Tansel and Bircan [6] studied "The Demand for education in Turkey: A Tobit analysis of private tutoring expenditures" in which the researchers indicate that private tutoring institution has become very popular, especially in East Asia, for example, in Egypt and Taiwan, where there have been widespread increase in the establishment of private tutoring institutions ([7], and [8]). This is because the majority of the students in the private tutoring institutions believe that having private tutoring will provide more chances to attend higher education, especially in countries that have very competitive admission examinations for universities with high reputations such as in South Korea, Greece, Japan, Turkey, etc. For developing countries, an important factor that induces competitiveness for admission is the small number of public universities available that insufficient to demands as all these universities have relatively low fees, and this does not include special courses. All these factors contribute to the student's need to study in private tutoring institutions in order to increase their own competitive potential. For this reason, Tansel and Birca wanted to study private tutoring expenditures of various households.

This research used data of private tutoring expenditures in households from 1994 survey data of household expenditures carried out by the State Institute of Statistics of Turkey. The data reported that 4,279 households that paid education fees even their children attend private schools, (public schools under the government require no-fee) as well as private tutoring expenditures. Within the these households, 646 have private tutoring expenditures whilst 3,252 households do not have any tutoring expenditures and only paid education fees. There was no data on the rest of the households. Researchers studied the Engel curve by using the Tobit regression model to demonstrate the relationship of the dependent variable and of course, the data on private tutoring expenditures had a lower limit of 0 . 
For this study, the dependent variable under study is the household private tutoring expenditure and 10 different independent variables, which are: the age of the head of the family, the age of the head of the family squared, the number of education years the head of the family, the number of education years of the mother and the independent variable that is the dummy variable as follows: work status and marriage status of the mother, residential area, road conditions (only for those liv i n g o u t $\mathrm{s}$ i d e municipality), tenancy status and number of children in the household. From evaluation results using the Tobit regression model via Maximum likelihood estimation, it was found that the important independent variable that has a linear influence on household private tutoring expenditure includes: household expenditure, age of the head of the family, age of the head of the family squared, the number of education years the head of the family and the mother, marriage status of the mother, residential area, and the number of children in the household. The results obtained were reasonable and there was sufficient evidence from Tansel and Bercan's [6] research.

From the research, it was found that the researchers presented regression coefficients, influence value of unconditional marginal effect and conditional marginal effect. With regards to the independent variable, there is a significant linear influence towards private tutoring expenditures $(p<0.01)$ with household expenditure having the highest regression coefficient $\left(\beta^{\wedge}=6.33\right)$.

The influence value of the unconditional marginal effect is 0.91 and the influence value of the conditional marginal effect is 1.21 , or in other

words, $\partial \hat{\mathrm{E}}(\mathrm{Y}) / \partial \mathrm{X}_{\mathrm{j}}=0.91$.

This can be explained to be the result only when other variables are constant.

An increase in the logarithmic value of household expenditures by 1 unit will make the logarithmic value of private tutoring expenditures increase by 6.33 units and if the value of the household expenditure increases by 1 percent, the value of private tutoring expenditures will increase by 0.91 percent or around 1 percent as well. For other variables, it can be explained using the same characteristics, which can be studied in the works of Tansel and Bercan.

Similarly, research done by Psacharopolus and [9] studied the relationship between private tutoring expenditures and household income. However, they found that household income did not have a linear influence towards household private tutoring expenditures. The inconsistency of these results may be because the researches used the ordinary least square linear regression analysis instead.

Apart from this, Stair, Rephan and Heberling [10] carried out research on "The desire to study in public schools: only in the municipality" where they applied the Tobit regression model and the method of maximum likelihood estimation. They studied the linear influence of the independent variable towards the dependent variable where the dependent variable in this study is the education fee willingly paid to enable the increase in quality of government institutions. Two areas were studied within local municipalities of Pennsylvania. The independent variables are as follows: 1) total household income, 2) total household income square, 3) main occupation, 4) education level of the head of the family, 5)-7) having children in the household in the education system, 8) household size, 9) age of the head of the family, 10) having children in the household that did not study in the government school within the residential area, 11) having children in the household attending school in the district, 12) the relationship between the household and those working in the schools under the jurisdiction of the government, 13) expectations of the parents towards the fulfillment of the children after school affiliated with the update and 14) main income of the household.

Results of the study after using the Tobit regression model revealed that within the Bedford area, the independent variable has an important linear influence towards the dependent variable in 5 variables, which are: total household income, total household income squared, the expectation of the parents towards the fulfillment of the children after school affiliated with the update and the relationship between the household and those working the schools under the jurisdiction of the government and having children in the household that did not study in the government school within the residential area.

At the same time within the Hyndman area, the independent variable has an important linear influence towards the dependent variable in 3 factors, which are: total household income, having children in the household in the education system and having children in the household attending school in the district.
The researches allowed us to know that recently, the Tobit regression has been used to analyse linear relationships in many different fields including data concerning education economics, for example: private tutoring expenses, the education fee willingly paid to enable the increase in quality of government institutions, total budget, income from education fees, personal salary, etc. All these data have lower limits, e.g.: personal salary would have a lower limit as the minimum revenue per day, living expenses, budget; or number of people will have a lower limit as 0 as seen in the two studies that the researchers mentioned above. When the data has this type of characteristics and the researcher still carries out ordinary least square linear regression analysis, the regression line produced will have an estimated slope that is underestimated, and is also a biased estimate when it approaches infinity.

Apart from this, there has also been theoretical research that discusses the application of the Tobit regression model and cases where problems with regression outliers arises, all of which are presented in Mekbunditkul's [2] work. The research found that the Tobit regression model is able to decrease the influence of some ( $y$ - direction outliers) .

\subsubsection{Economics analysis of data using the Tobit-piecewise regression model}

Researchers have taken the Tobit-piecewise regression model to use in the evaluation of regression that had problems with outliers and found that the Tobit-piecewise regression model gave different results to the one obtained from using the ordinary least square linear regression analysis. An example of this is research done by Thipbharos [11] who updated the Tobit-piecewise regression model by using principles of segment information by using cluster analysis and using the regression model obtained to use in the evaluation to find the factor that had an influence on education debt for children in the household. The factors studied were: household expenses, education expenses, the education level of the head of the family, household income, the age of the head of the family, the household assets, education funding their children receive, administrative region, household size, household debt and the number of children currently studying. The researcher used the 2011 economic survey data and household social status data produced by the National Statistical Office and chose only households that had children currently studying in an institution, from kindergarten to doctorate, which amounted to 10,261 households.

Results from the Tobit-piecewise regression model revealed that the regression model to predict education debt has three models, which are models for poor, middle-income and high-income households. The results of the analysis indicated that there are different factors influencing household education debt. For poor households, significant influential factors found using the Tobit-piecewise regression model are: education expenditures, household size and household debt. For middle-income households, significant influential factors are: household income, household debt and the number of children who are currently studying. For high-income households, significant influential factors on education debt are: the age of the head of the family, household size and household income. Apart from that, analysis results showed that if the researchers used the ordinary least square linear regression analysis, significant factors would be different from what was described. Analysis also showed that different economic status of the households result in different types of debts for each of the households.

Later, Thipbharos (2015) developed a regression model called the Adjusted regression, which is a model developed from the Tobit-piecewise regression model in order to deal with the problem of outliers that arise from regression analysis. The researcher designated the outlier to have the same value as the upper limit and/or lower limit of the confidence band of the individual prediction. The researcher applied the regression analysis developed to use in the determination of the influence of various factors towards the expenditure of agricultural insurance in Thailand. Thipbharos's [12] research compared the suitability of models using the average sum square residual (ASSR), which was developed by Mekbunditkul (2010) and found that the adjusted regression model gave a lower ASSR value than the result obtained from the Piecewise regression model. The data used in the evaluation was obtained from the 2013 economic survey data and household social status data produced by the National Statistical Office, where the number of agricultural households was 5,3243 .

The main factors studied on its influence on the expenditure of agricultural insurance in Thailand are: cultivating area, the education level of the head of the family, the age of the head of the family, household size and household income. Results from this analysis found that results using the adjusted regression model gave rise to two different regression 
models for the prediction of the expenditure of agricultural insurance for poor household and non-poor household. It is clear that influential factors for each are different. For poor households, the influential factors are: the education level of the head of the family and household income whereby the education level of the head of the family has a greater influence. For non-poor households, important factors are: age and the income of the head of the family, and it was found that the age of the head of the family had a greater influence. Apart from that, results of the research found that the adjusted regression model had a lower ASSR value than that of the Piecewise regression model.

\section{The Process of Applying the Tobit-Piecewise Regression Model}

The evaluation of the Tobit regression model has been used in the evaluation of the linear influence between variables in a widespread manner in cases where the dependent variable has an upper limit and/or lower limit. The Tobit regression model has been used in many different fields, especially in situations where the data concerns economics, for example: income, expenditure, budgets, etc.

In regards to the Tobit-piecewise regression model, it has been developed to deal with problems of outliers within the data and it decreases the influence of the outliers by weighing its value around the upper limit or the lower limit. This would make the regression model more suitable than the ordinary least square linear regression analysis. Dealing with the outliers in this manner is considered a robust method that is less difficult and complicated than other robust regression methods.

In the case of when the data has an upper limit and/or lower limit, it has been clearly and theoretically proven in the research done by Greene (1981) that the ordinary least square linear regression analysis results in a biased regression equation with the characteristic that the estimate is an understimate and that it is also a biased estimate as it approaches infinity. Therefore, the researcher should be very careful when analysing these types of data. Apart from that, the interpretations of the regression coefficients in the Tobit regression model and in the Tobit-piecewise regressin model can be interpreted in two ways: the change in dependent variable when the independent variable changes by one unit and the changes in the probability of the dependent variable. Interpreting these results should be extremely useful for the researcher. Nevertheless, the Tobit regression model and the Tobit-piecewise regression model has the same assumptions as the ordinary least square linear regression analysis.

The results of research done by Mekbhunditkul (2010) and Thipbharos (2014, 2015) informs us that the Tobit-piecewise regression and the adjusted regression has good capability of decreasing the influence of $(y$ - direction outliers) and decrease the influence of ( $\mathrm{x}$ - direction outliers) as well as in (xy - direction outliers) in some cases. Another interesting results from the creation of a model from concept of the piecewise regression model is that the model obtained will be suitable in cases where the data analyzed are not harmonious for all data sets. This may results from when the population distribution is different or there are changes in the structure of the data. Therefore, evaluating regression for 1 data set only with a single regression line may no longer be suitable with present data.

\section{References}

1. Rousseeuw, P.J. and Leroy, A. M., "Robust Regression and Outlier detection", New York : John Wiley \& Sons, 1987,

2. Mekbunditkul, T., "An Alternative Estimation for Regression Coefficients with Outliers", Dissertation, Bangkok: National Institute of Development Administration, 2010,.

3. Tobin, J., "Estimation of Relationships for Limited Dependent Variables", Econometrica, 26,24- 36, 1958,.

4. Quandt, R.E., "The estimation of the Parameters of a Linear Regression System Obeying Two Separate Regimes", Journal of the American Statistical Association, 53, 873-880, 1958,.

5. McDonald, J.F. and Moffitt, R.A., "The Uses of Tobit Analysis", The Review of Economics and Statistics, 62(May), 318-321, 1980,

6. Tansel,A. and Bircan, F., "Demand for education in Turkey: A tobit analysis of private tutoring expenditures", Economics of Education Review, 25, 303-313, 2006,

7. Bray, M., "The shadow education system: Private tutoring and its implications for planners",Fundamentals in Educational Planning, Paris: UNESCO International Institute for EducationalPlanning (IIEP), 1999,.

8. Bray, M. and Kwok, P., "Demand for private supplementary tutoring: Conceptualconsiderations and socio-economic patterns in Hong Kong", Economics of Education Review,22, 611-620, 2003,.

9. Psacharopoulos, G. and Papakonstantinou, G., "The real university cost in a "free" highereducation country", Economics of Education Review, 24(1), $103-108,2005$,

10. Stair, A., Rephann, T. and Heberling, M., "Demand for public education: Evidence from a ruralschool district", Economics of Education Review, 25, 521-531, 2010,.

11. Thipbharos, T., "What can Tobit-piecewise regression tell us about the determinants ofhousehold educational debt?", Journal of International Education Studies, 7(4), 1-13, 2014,

12. Thipbharos, T., "The Derivation of Maximum Likelihood Estimation for Linear Relation withOutliers", International Journal of Applied Mathematics and Statistics, 53(3), 2015, 